\title{
Adaptability Evaluation of Common Bean (Phaseolus vulgaris L.) Varieties in South-East Arsi Zone, Ethiopia
}

\author{
Gebeyaw Achenef*, Aliy Robsa, Deresa Tesfaye, Kedir Yimam \\ Ethiopian Institute of Agricultural Research, Kulumsa Agricultural Research Center, Assela, Ethiopia
}

\author{
Email address: \\ gebesday08@gmail.com (G. Achenef) \\ ${ }^{*}$ Corresponding author
}

\section{To cite this article:}

Gebeyaw Achenef, Aliy Robsa, Deresa Tesfaye, Kedir Yimam. Adaptability Evaluation of Common Bean (Phaseolus vulgaris L.) Varieties in South-East Arsi Zone, Ethiopia. International Journal of Applied Agricultural Sciences. Vol. 7, No. 4, 2021, pp. 156-161.

doi: $10.11648 /$ j.ijaas.20210704.13

Received: July 5, 2021; Accepted: July 19, 2021; Published: July 24, 2021

\begin{abstract}
Common bean (Phaseolus vulagris L.) is a very important legume crop grown worldwide and adapted mid to high altitude areas of Ethiopia. The experiment was conducted on both Farmer's Training Center (FTC) and Kulumsa research stations of East Arsi zone. The purpose of the study was to select elite and adapted common bean varieties that will maximize productivity and production of common in the target areas. Nine improved common bean varieties were used for this study. The experiment was carried out using a randomized complete block design (RCBD) with three replications for two growing season (2019-2020) under rain fed condition. The combined ANOVA result indicated, significant difference $(\mathrm{P}<0.001)$ among variety, Location and their interaction were observed for all parameters (days to flowering, days to maturity, plant height, seed yield, Number of pod per plant, except number of seed per pod which was non-significant due to variety $\mathrm{x}$ location interaction. The first and the second IPCA of AMMI biplot were significant $((\mathrm{P}<0.001)$ and $85.1 \%$ the variations were explained together. Based on the scatter plot of PC1 against PC2, V8 (SER-119) and V7 (SER-125) were more adapted varieties in most of the locations across two growing seasons whereas, V5 was stable variety Among the tested varieties, the highest seed yield per hectare was obtained from variety SER-125 (3190.4 $\left.\mathrm{kgha}^{-1}\right)$ and SER-119 (3090.3 $\left.\mathrm{kgha}^{-1}\right)$ whereas the lowest yield was obtained from variety SAB-736. Therefore, the Variety SER-125 and SER-119 can be recommended as selected varieties and to be promoted in the study areas.
\end{abstract}

Keywords: Adaptation, AMMI, Interaction, Location, Variety, Yield

\section{Introduction}

The Common bean (Phaseolus vulgaris L.) is important herbaceous annual grain legume in the world. Manly common bean is grown as an affordable source of protein for the majority of Sub-Saharan African people [6]. The crop is originated in tropical America (Mexico, Guatemala, and Peru) and domesticated to Central-America (CIAT, 1986a). In the $16^{\text {th }}$ century common bean is introduced to Ethiopia by the Portuguese [4] Common bean (Phaseolus vulgaris L.) is the most important grain legume and adapted mid to high altitude areas of Ethiopia but the suitable production areas have been indicated $(1200-2200$ m.a.s.l), with rainfall of 350-500 mm well distributed over 70-100 days [13]. The crop is grown by subsistence farmers either as a sole crop and/or intercropped with either cereal or tree crops.
In Ethiopia, common bean is used us rotational crop to improve soil fertility and it is one of the most important cash crops and an emergency crop to reduce hunger since it is source of protein, starch, dietary fiber and is an excellent source of potassium, selenium, molybdenum, thiamine, vitamin B6 and folic acid [2] Where they are consumed as Nifro, Shirowet, soup and samosa. In a plant breeding context, adaptation is the ability of the material to be highyielding with respect to a given environment or given conditions to which it is adapted [8] Moreover, adaptability is the ability to show good adaptedness in a wide range of environments [16].

Varietal adaptation under the Ethiopian Institute of Agricultural Research (EIAR) and Regional Agricultural Institutes (RARIs) with the support from the International Center of Tropical Agriculture (CIAT) resulted into higher 
yielding improved common bean varieties that are potentially suitable for a range of ecologies (from lowlands to highlands). These improved varieties were also highly appreciated by consumers and market but farmers continued to grow low yielding old varieties instead [2] The analysis of constraints hindering use of improved varieties with stakeholders revealed that the main constraint to adoption of bean improved varieties was associated with limited accessibility to seed [2] Much research has been done on common bean varietal adaptation for performance evaluation in Ethiopia $[14,1]$ and many improved common bean varieties have been adopted in low-land agro-ecology of Ethiopia. However, an adaptation study in mid-agro ecology of East Arsi zone is important to guarantee the improvement of the crop and it can be a solution to reduce mono-cropping and soil fertility restoration for sustainable agricultural production. Thus there is need to introduce the improved common bean varieties released in Ethiopia to the target area that makes an important and novel contribution to improve the productivity of the crop. Therefore, the study was initiated with the objective of selecting high yielder improved common bean varieties in the study area in terms of seed yield and related attributes.

\section{Materials and Methods}

\subsection{Description of the Study Area}

The study was conducted at three locations (Kulumsa, Assasa and Zuway Dugda) from 2019-2020 two main cropping seasons.

Table 1. Description of Experimental site.

\begin{tabular}{|c|c|c|c|c|c|c|c|c|}
\hline \multirow{2}{*}{ NO. } & \multirow{2}{*}{ Location } & \multicolumn{2}{|c|}{ Global Position } & \multirow{2}{*}{$\begin{array}{l}\text { Altitude } \\
\text { m.a.s.l }\end{array}$} & \multirow{2}{*}{$\begin{array}{l}\text { Average } \\
\text { Rainfall }\end{array}$} & \multicolumn{2}{|c|}{ Temperature } & \multirow{2}{*}{ Soil } \\
\hline & & Longitude & Latitude & & & Min. & Max. & \\
\hline 1 & Kulumsa & $39^{\circ} 09^{\prime} 32^{\prime \prime} \mathrm{E}$ & $08^{\circ} 01^{\prime} 00^{\prime \prime} \mathrm{N}$ & 2200 & 820 & 11 & 23 & clay \\
\hline 2 & Zuway-Dugda & $38^{\circ} 43^{\prime} 0^{\prime \prime} \mathrm{E}$ & $7^{\circ} 55^{\prime} 59^{\prime \prime} \mathrm{N}$ & 740 & - & - & - & clay \\
\hline 3 & Assasa & $39^{\circ} 11^{\prime} 32^{\prime \prime} \mathrm{E}$ & $07^{\circ} 06^{\prime} 12^{\prime \prime} \mathrm{N}$ & 2300 & 620 & 6 & 24 & clay \\
\hline
\end{tabular}

\subsection{Experimental Procedures and Plant Materials}

Nine improved common bean varieties (Awash-1, Awash-2, Awash Melka, Nasir, SCR-11, SCN-5, SER-125, SER-119 and SAB-736) hosted from Melkasa Agricultural Research Center was conducted during the main cropping season of 2019/2020. The varieties were laid in Randomized Complete
Block Design (RCBD) with three replications having plot size of $7.2 \mathrm{~m}^{2}(4 \mathrm{~m} \times 1.2 \mathrm{~m})$, accommodating 6 rows of $4 \mathrm{~m}$ length. The spacing between rows and plants was $30 \mathrm{~cm}$ and $10 \mathrm{~cm}$, respectively. Harvesting was done from four central rows and each plot has net harvestable area of $4.8 \mathrm{~m}^{2}$. All necessary agronomic packages were applied as per the recommended package for common bean.

Table 2. Descriptions of Varieties used for the experiment.

\begin{tabular}{|c|c|c|c|c|c|}
\hline NO. & Variety name & Year of release & seed size & Color & Altitude \\
\hline 1 & Awash-1 & 1974 & Small & White & $1450-2000$ \\
\hline 2 & Awash-2 & 2013 & Small & White & $1450-2000$ \\
\hline 3 & Awash Melka & 1999 & Small & White & $1450-2000$ \\
\hline 4 & Nasir & 2003 & Small & Red & $1450-2000$ \\
\hline 5 & SCR-11 & - & Small & Red & $1450-2000$ \\
\hline 6 & SCN-5 & - & Small & black & $1450-2000$ \\
\hline 7 & SER-125 & 2014 & Small & Red & $1450-2000$ \\
\hline 8 & SER-119 & 2014 & Small & Red & $1450-2000$ \\
\hline 9 & SAB-736 (Ado) & 2015 & Small & White & $1450-2000$ \\
\hline
\end{tabular}

\subsection{Data Recorded and Analysis}

The measured parameters were crop phenology (days to $50 \%$ flowering (DTF), days to physiological maturity (DTM)); growth parameters (plant height (PTH)) and yield parameters (number of pods plant ${ }^{-1}$ (NPPL), number of seeds $\operatorname{pod}^{-1}$ (NSPD) and seed yield hectare ${ }^{-1}$ (SYHA)). DTF and DTM were recorded for each variety on the plot by regular observation, when $50 \%$ of the plants flowered, as days to $50 \%$ flowering and when $90 \%$ of the pods in a plot dried, as days to physiological maturity of each plot. At physiological maturity, five plants from central rows were randomly selected and measured. At harvest, five plants were randomly collected and yield components like NPPL and NSPD were recorded. Grain yield was harvested from four central rows of each plot $\left(4.8 \mathrm{~m}^{2}\right)$ and measured in gm finally adjusted to standard moisture content for analysis. All measured parameters (crop phenology, growth parameters, grain yield and yield components) were subjected to analysis of variance (ANOVA) using linear mixed model; replication, location and interactions were random; Variety as a fixed effect [17]. ANOVA was performed using the following multiplicative model;

$$
\mathrm{R}_{\mathrm{ijr}}=\mathrm{m}+\mathrm{V}_{\mathrm{i}}+\mathrm{L}_{\mathrm{j}}+\mathrm{B}_{\mathrm{r}}\left(\mathrm{L}_{\mathrm{j}}\right)+\mathrm{VL}_{\mathrm{ij}}+\mathrm{e}_{\mathrm{ijr}},
$$

Where $R_{i j r}=$ the response variable $m=$ grand mean; $V=$ Variety, $L=$ location and $B=$ block effects; $V L_{i j}=$ Variety by location interaction; and $e_{i j r}=$ random error. PROC Mixed Method $=$ reml (restricted maximum likelihood) of SAS software version 9.0 were employed i.e. "repeated/ group=Location" after the 
random statement in SAS Procedure to handle different residual variances at each location [10] and the significance of mean differences were tested by least significant difference test $p \leq 0.05$ (LSD) as stated in [12]. The AMMI analysis was performed using the following additive and multiplicative in to a single model suggested by [8]:

$$
Y_{i j}=\mu+G_{i}+E_{j}+\sum_{n=1}^{n} \lambda_{\mathrm{n}} \alpha_{\mathrm{in}} \mathrm{y}_{\mathrm{jn}}+e_{i j k}
$$

Where, $Y_{i j}$ is the yield of the $i^{\text {th }}$ genotype in the $j^{t h}$ environment, $\mu$ is the grand mean, $G_{i}$ is the mean of the $i^{t h}$ genotype minus the grand mean, $E_{j}$ is the mean of the $j^{\text {th }}$ environment minus the grand mean, $\lambda_{\mathrm{n}}$ is the square root of the Eigen value of the principal component analysis (PCA) axis $\alpha_{\text {in }}$ and $y_{\text {in }}$ are the principal component scores for PCA axis $\mathrm{n}$ of the $i^{\text {th }}$ genotype and $j^{\text {th }}$ environment and $e_{i j k}$ is the error term

\section{Results and Discussion}

The combined analysis of variance result (Table 2) showed that the mean square due to variety, location, replication variety by location were highly significant difference at $(\mathrm{P}<0.001)$ for all measured traits like SYLD, DF, NPPL, NSPP and PH. However, DF was not significantly differed for the mean square due to replication and variety by location interaction. The sums of square to location were high for all measured traits these indicated that most of the variations were explained by the traits. The significance variety by location interaction effect revealed that the tested varieties were do not perform equally well over all locations or the environmental influence was high for the respected parameters.

\subsection{Variation of Growth, Phenology and Yield Component Traits}

Combined Analysis of variance obtained from the studied traits of common bean was indicated in (Table 2). According to the result, there were presences of highly significant difference at $(\mathrm{P} \leq 0.01)$ due to variety, location and location by variety interaction for the traits; days to $50 \%$ flower (DTF), the time taken to be mature (DTM), height of plant (PH), Number of pod per plant (NPPL). However, no significant varietal differences observed in days to flowering (DF) due to variety $\mathrm{X}$ location interaction this implies that the time to flower dose not influenced by location differences.

These results in line with $[11,15,1]$ they reported significance varietal difference in improved chickpea and common bean variety adaptation study

Table 3. Combined Analysis of Variance for nine common bean varieties grown for two years in three locations.

\begin{tabular}{|c|c|c|c|c|c|c|c|c|c|c|}
\hline \multicolumn{11}{|c|}{ Source of variation due to } \\
\hline \multirow{2}{*}{ Traits } & \multicolumn{2}{|c|}{ Variety $(\mathrm{df}=8)$} & \multicolumn{2}{|c|}{ Location $(\mathrm{df}=\mathbf{5})$} & \multicolumn{2}{|c|}{ Replication (df $=12)$} & \multicolumn{2}{|c|}{ Variety $x$ Location $(\mathrm{df}=\mathbf{4 0})$} & \multicolumn{2}{|c|}{ Error $(d f=96)$} \\
\hline & SM & MS & SM & MS & SM & MS & SM & MS & SM & MS \\
\hline SYLD & 22718820 & $2839853^{* *}$ & 44370562 & $8874112^{* *}$ & 4906782 & $408899^{*}$ & 23548620 & $588716^{* *}$ & 21316804 & 222050 \\
\hline DF & 271.2 & $33.9^{* *}$ & 5756.42 & $1151.283951^{* *}$ & 60.5926 & $5.049383^{\mathrm{ns}}$ & 214.246914 & $5.356173^{\mathrm{ns}}$ & 360.7 & 3.8 \\
\hline DM & 347.8 & $43.5^{* *}$ & 13401 & $2680.217284^{* *}$ & 30.5185 & $2.54321^{* *}$ & 366.246914 & $9.156173^{* *}$ & 390.1 & 4.1 \\
\hline NPPL & 1879.9 & $234.9^{* *}$ & 7524.327 & $1504.865432^{* *}$ & 255.63 & 21.30247 & 1848.17284 & $46.204321^{* *}$ & 2739.7 & 28.5 \\
\hline NSPP & 16.1 & $2.0^{* *}$ & 30.40124 & $6.080247^{* *}$ & 4.2963 & $0.358025^{* *}$ & 22.432099 & $0.560802^{* *}$ & 36.4 & 0.4 \\
\hline $\mathrm{PH}$ & 1774.5 & $221.8^{* *}$ & 2036.803 & $407.360593^{* *}$ & 490.877 & $40.90642^{* *}$ & 1699.672593 & $42.491815^{*}$ & 2060.0 & 21.5 \\
\hline
\end{tabular}

Where, $\mathrm{SYLD}=$ seed yield, $\mathrm{df}=$ degree of freedom, $\mathrm{DM}=$ Days to physiological maturity, $\mathrm{DF}=$ Days to $50 \%$ flowering, $\mathrm{NPPL}=$ number of pod per plant, $\mathrm{NSPP}=$ number of seed per pod and $\mathrm{PH}=$ plant height

In contrast,[5] reported, those days to maturity and number of pod per plant were not significant differences in variety $\mathrm{x}$ location interaction however; this finding is similar with the result for number of seeds per pod which was stable component across location. Based on the combined mean performance result the late flowered variety were Awashi-Melaka followed by SER-119 and early flowered and matured variety was SAB-736. This variety is selected for low moisture or terminal moisture bean production areas. The longest days has been taken for maturity was variety Awash-2 followed by variety Awash-1.

The highest number of pods per plant was recorded from varieties Awash-1 and Awash-2 and the lowest number of pod per plant were obtained from SAB-736 and SER-119. The highest plant height was obtained from Awsah-2 followed by SER-125 similarly the lowest plant height was recorded from variety SAB-736 and Awash-Melka (Table 3).

Table 4. Combined mean performance of phonological, growth and yield component traits of Small seed common bean variety across three locations in two cropping seasons (2019-2020).

\begin{tabular}{llllll}
\hline Variety & DF & DM & NPPL & NSPP & PH \\
\hline Awash-1 & 55.0 & 111.5 & 26.2 & 5.1 & 44.2 \\
Awash-2 & 55.1 & 112.6 & 25.1 & 5.3 & 49.5 \\
Awash Melka & 55.5 & 109.8 & 21.9 & 5.8 & 44.1 \\
Nasir & 53.6 & 108.8 & 20.4 & 5.3 & 46.3 \\
SCR-11 & 54.3 & 108.1 & 18.5 & 5.6 & 44.4 \\
SCN-5 & 55.1 & 109.7 & 18.0 & 5.4 & 44.4 \\
SER-125 & 54.3 & 110.2 & 18.6 & 4.8 & 48.0 \\
SER-119 & 55.2 & 110.2 & 16.6 & 5.3 & 45.5 \\
SAB-736 & 51.1 & 107.7 & 15.9 & 4.7 & 36.9 \\
G/mean & 54.4 & 109.8 & 20.1 & 5.3 & 44.8 \\
LSD (5\%) & 1.3 & 1.3 & 3.5 & 0.4 & 3.1 \\
CV (\%) & 3.6 & 1.8 & 26.5 & 11.7 & 10.3 \\
SE & 0.51 & 0.75 & 0.74 & 0.06 & 0.56 \\
\hline
\end{tabular}




\subsection{Mean Performance of Common Bean Seed Yield at Three Locations for Two Years}

It can be observed that at Asasa site, variety Nasir gives the highest seed yield $(2996.7 \mathrm{~kg} / \mathrm{ha})$ in 2019 cropping season followed by SCR-11 $(2745.2 \mathrm{~kg} / \mathrm{ha})$ but variety SAB-736 gives the lowest seed yield (Table 4). At Kulumsa Centre and Zeway-Dugda, variety SER-125 and SER-119 produces the highest seed yield, though statistically it is at par with Variety Nasir, SCN-5 and SER-11 in the two years cropping season
(Table 4). Among nine varieties the combined mean performance of seed yield across the three locations variety SER-125 is out yielded with mean yield (3190.4 kg/ha) followed by SER-119 (3094.3 kg/ha) it is at par with varieties SCN-5 and Nasir across all locations. Variety SAB-736 gives the lowest seed yield almost across all locations. Similarly (Bucheyeki, 2013) reported that, there were high significant yield differences among bean varieties across three seasons $(P<0.001)$. The highest and the lowest seed yield were obtained from SER-119 and SAB-736 [15].

Table 5. Location Wise Treatment Means and combined mean performance for common bean yield across two years.

\begin{tabular}{|c|c|c|c|c|c|c|c|}
\hline \multirow{3}{*}{ Variety } & \multicolumn{3}{|l|}{ Year-2019 } & \multicolumn{4}{|l|}{ Year-2020 } \\
\hline & \multicolumn{7}{|l|}{ Locations } \\
\hline & Y1L1 & Y1L2 & Y1L3 & Y2L1 & Y2L2 & Y2L3 & Mean \\
\hline Awash-1 & $2066.1^{a}$ & $2939.3^{c}$ & $3214.5^{\mathrm{ab}}$ & $1625.6^{\mathrm{abc}}$ & $1635.7^{\text {ef }}$ & 2709.4 & $2365^{\mathrm{e}}$ \\
\hline Awash-2 & $1698.6^{\mathrm{b}}$ & $2203.6^{d}$ & $3158.3^{\mathrm{ab}}$ & $2003.4^{\mathrm{abc}}$ & $1420^{\mathrm{f}}$ & 2481.3 & $2160^{\mathrm{e}}$ \\
\hline Awash Melka & $2458.9^{\mathrm{a}}$ & $2896^{\mathrm{c}}$ & $2961.7^{\mathrm{a}}$ & $1419.1^{\mathrm{bc}}$ & $1325.4^{\mathrm{f}}$ & 2440.1 & $2250.2^{\mathrm{e}}$ \\
\hline Nasir & $2996.7^{\mathrm{a}}$ & $4249.9^{\mathrm{a}}$ & $2875^{\mathrm{d}}$ & $2114.5^{\mathrm{abc}}$ & $2285.5^{\mathrm{c}}$ & 2302.4 & $2804^{\mathrm{bc}}$ \\
\hline SCR-11 & $2745.2^{\mathrm{a}}$ & $3467.4^{\mathrm{b}}$ & $3556.2^{\mathrm{a}}$ & $1918.2^{\mathrm{abc}}$ & $2067.3^{\mathrm{dc}}$ & 2368.4 & $2687.1^{\mathrm{dc}}$ \\
\hline SCN-5 & $2185.9^{\mathrm{a}}$ & $3717.3^{b}$ & $3345.2^{\mathrm{ab}}$ & $2376.8^{\mathrm{ab}}$ & $2838.2^{\mathrm{b}}$ & 3060.3 & $2920.6^{\mathrm{abc}}$ \\
\hline SER-125 & $2080.5^{\mathrm{a}}$ & $4494^{\mathrm{a}}$ & $3212.3^{\mathrm{ab}}$ & $2581.2^{\mathrm{a}}$ & $3438.7^{\mathrm{a}}$ & 3335.8 & $3190.4^{\mathrm{a}}$ \\
\hline SER-119 & $2540.9^{\mathrm{a}}$ & $4288^{\mathrm{a}}$ & $3450.9^{\mathrm{ab}}$ & $2288.4^{\mathrm{ab}}$ & $3479.7^{\mathrm{a}}$ & 2517.6 & $3094.3^{\mathrm{ab}}$ \\
\hline SAB-736 & $1638.4^{\mathrm{b}}$ & $2681^{\mathrm{c}}$ & $2496.3^{\mathrm{e}}$ & $1186.6^{c}$ & $1898.9^{\mathrm{de}}$ & 2500.1 & $2066.9^{\mathrm{e}}$ \\
\hline G/mean & 2267.9 & 3437.4 & 3141.2 & 1946 & 2265.5 & 2635 & 2615.5 \\
\hline $\mathrm{SE}(\mathrm{d})$ & 120.9 & 55 & 45.6 & 124.4 & 42 & 173 & 93.5 \\
\hline LSD (0.05) & 1132 & 409.9 & 337 & 1068.7 & 377 & 1290 & 331.5 \\
\hline $\mathrm{CV}$ & 19 & 6.8 & 6.2 & 22 & 9.6 & 6.5 & 19.2 \\
\hline
\end{tabular}

***Means with different letter, significantly differed each pair wise comparison and having the same letter was not significant difference

\subsection{Additive Main Effect and Multiplicative Interaction (AMMI) Model}

The additive main effects and multiplicative interactions (AMMI) analysis of nine common bean varieties across six environments was performed (Table 5), and the model partitioned $\mathrm{V} \times \mathrm{L}$ in to different IPCA and residual term. The mean square of IPCA1 and IPCA2 were found significant. However, IPCA3 was not significant. The significance of MS of environment indicated the test environments were very diverse and causing most of the variations in seed yield. The first and the second interaction principal component axis explained $59.8 \%$ and $25.3 \%$ of the total $\mathrm{G} \times \mathrm{E}$ interaction (Figure 1). The two IPCAs explained about $85.1 \%$ of the total genotype $\mathrm{x}$ environment interaction sum of square. The variety sum of squares (SS) accounted for the $11.2 \%$ of the variability's out of the total treatment variation and most of the variation was accounted by location from the total treatment variation components. In addition, results further showed that $\mathrm{G} \times \mathrm{E}$ interactions were superior to environment effects.

Table 6. AMMI analysis of variances of nine bean varieties across six environments.

\begin{tabular}{|c|c|c|c|c|c|c|}
\hline SOV & Df & SS & MS & SS\%(G x E) & F-test & Pro. \\
\hline Total & 161 & 116861588 & 725848 & & & \\
\hline Treatments & 53 & 90638002 & 1710151 & 44.7 & 7.7 & $<0.001$ \\
\hline Varieties (V) & 8 & 22718820 & 2839853 & 11.2 & 12.8 & $<0.001$ \\
\hline Locations (LOC) & 5 & 44370562 & 8874112 & 21.9 & 21.7 & $<0.001$ \\
\hline Rep (Loc.) & 12 & 4906782 & 408899 & 2.4 & 1.8 & 0.05 \\
\hline Interactions (V x Loc.) & 40 & 23548620 & 588716 & 50 & 2.7 & $<0.001$ \\
\hline IPCA-1 & 12 & 14088498 & 1174042 & 29.9 & 5.3 & $<0.001$ \\
\hline IPCA-3 & 8 & 2229606 & 278701 & 4.7 & 1.3 & 0.3 \\
\hline Residuals & 10 & 1268922 & 126892 & 2.7 & 0.6 & 0.8 \\
\hline Error & 96 & 21316804 & 222050 & 10.5 & & \\
\hline
\end{tabular}

According to the biplot (Figure 1) indicated greater the distance from the origin, the greater the contribution to the $\mathrm{V}$ $x$ L interaction; at the location ASY1 (Assasa Year one) and KulY2 (Kulumsa year two) contributed high $\mathrm{V} \times \mathrm{L}$ interaction. Regardless of their mean yield, V1 and V2 along with the locations Assasa and Zeway Dugda have small distance from the origin indicated, low V x L interaction. All locations showed a considerable interaction. There was no 
location or variety in the center, which might be representative for the set of locations at which the trial was conducted. The greater the distance or the angle between two locations/varieties the more dissimilar they were, the obtuse angle between the location Assasa and Kulumsa or between Assasa and Zewy Dugda or Kulumsa and Zeway Dugda were indicated dissimilar in discriminating the varieties across year. On the other hand the direction from the center of a genotype and locations is similar, and then both contribute in the similar direction to the trait. The variety V7, V8 and V4 fits well to the location Kulumsa and has small angle between KUY2 and KUY1; V5 to Asasa; similarly V1, V2 and V3 to Zeway Dugda since the acute angle between ZDY1 and ZDY2 described positive correlation to the variety across year (Figure 1).

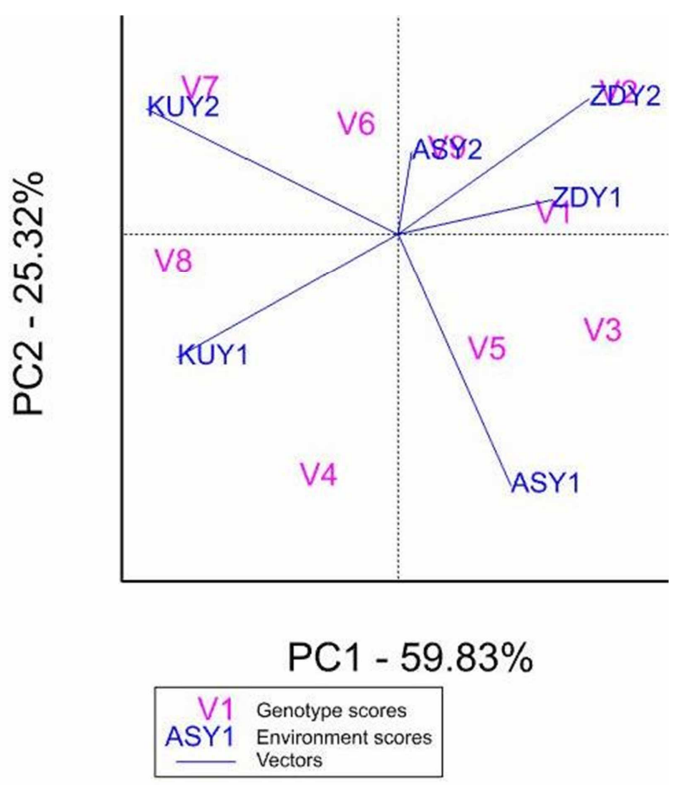

Figure 1. AMMI-2 biplot for seed yield showing the interaction of IPCA2 against IPCA1 score of common bean varieties (V1...V9) grown at three locations for two years.

The scatter plot (Figure 2) showed that, the ordinate (yaxis) represent $\mathrm{PC} 2$ or the interaction and abscissa (x-axis) represent $\mathrm{PC} 1$ or the main effect (genotype or environment) scores. Therefore, it provides opportunity to visualize the mean performance of genotype and environment as well as stability using IPCA1 simultaneously. The IPCA1 score for nine bean varieties and six environments were plotted against the mean yield of variety and environments (Figure 2). Varieties or environments on the right side of the midpoint of the axis have higher yields than those on the left hand side. Therefore, varieties found on the right side of the midpoint of the X-axis; V5, V4, V8, V7 and V6 were gave high yield i.e. above the overall mean yield but Varieties found on the left side of the mid-point were provided less yield. On the other hand V1, V3, V2 and V9 were not adaptable in all testing locations. In terms of year and location, V4 was the highest at Assasa (Y1L1; year one location one) and V8, V7 were more adapted varieties in most of the locations across two growing seasons whereas, V5 was stable variety and it was performed equivalent to the grand mean in all of the tested locations and growing seasons.

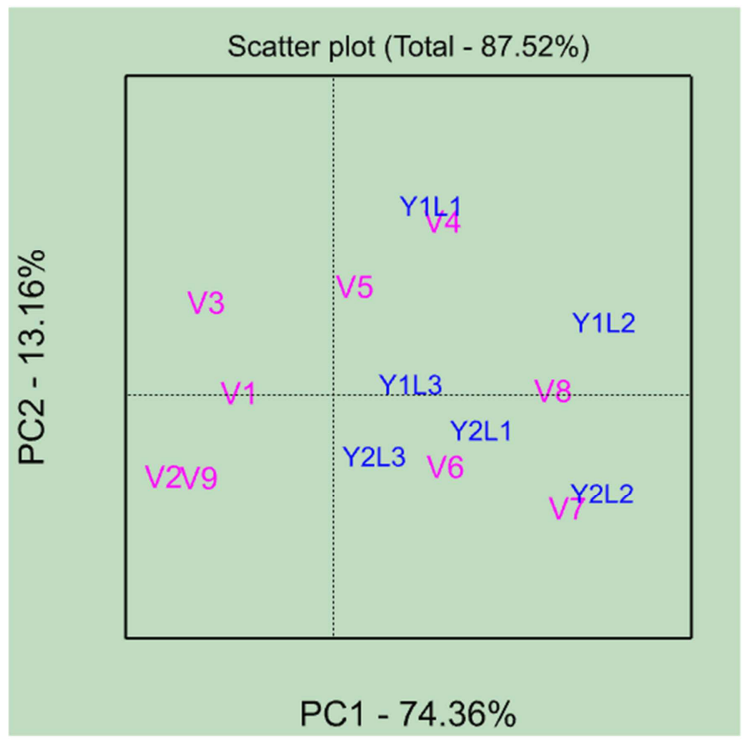

Figure 2. Plot of common bean variety yield performance across three location in two cropping season.

Y1L1...Y1L3 year one at location one; Y2L1 year two at location one (L1; Asasa, L2; Kulumsa and L3; Zeway dugda)

\section{Conclusion and Recommendations}

According to this findings there were significant differences among common bean varieties at $(\mathrm{P}<0.001)$ in all traits due to location, variety and variety by location interaction except number of seeds per pod which was nonsignificant in variety by location interaction. Among the tested varieties the highest seed yield per hectare were obtained from variety SER-125 and SER-119 respectively followed by variety SER119 across different cropping season and locations. Therefore, the Variety SER-125 and SER-119 can be recommended as selected varieties and to be promoted in the study areas. The area where this experiment was conducted is known by mono cropping system as a result the yield is far below the potential due to low soil fertility and disease infestation. Hence, common bean is crucial crop to ameliorate soil fertility and used as break crop to boost agricultural production. Besides, the common bean is miracle source of income for farmers and seed producers particularly the white color bean varieties are the highest commercial hence, good for local market and foreign currency. Finally, the highest yield response of the varieties to the study locations revealed that, the environments were found suitable for common bean production, despite the tested locations were favorable for production of common bean further investigations has to be conducted on other agronomic and crop management packages having similar agro-ecologies.

\section{Acknowledgements}

We extend our heart-felt thanks to Ethiopian Institute of 
Agricultural Research (EIAR) and Kulumsa research center funding money for this field experiment work. We are greatly intended to Dr. Brihanu Amsalu for his integrity and providing experimental materials. We also grateful Zeway Dugda wereda Development agents (DA) for providing their Farmer Training Center (FTC) and there unsaved assistance.

\section{References}

[1] Alemu, B. and Abera, D. (2014). Adaptation Study of improved Haricot beans (Phaseolus Vulgaris L.) Varieties at Western Oromia, Haro Sabu, Ethiopia. Advances in Life Science and Technology, 25.

[2] Amanuel A, Girma A. Production Status and adoption of improved Common bean (Phaseolus vulgaris L.) (2018). Varieties Associated with Agronomic Practices in Ethiopia. J Plant Sci Res. 5 (1): 178.

[3] Amare Abebe and Haile Kefene (1989). Country reports Eastern Africa. Ethiopia. p. 110- 120. In: proceedings of a workshop on bean varietal improvement in Africa. Maseru, Lesotho. 30 Jan- 2 Feb., 1989. CIAT African Workshop series No 4.

[4] Assefa, G. (1985). The mineral industry of Ethiopia: present conditions and future prospects. Journal of African Earth Sciences (1983), 3 (3), 331-345.

[5] Awel Beshir, Demeke Lea and Tesfaye Belay (2021). Evaluation of Recently Released Common Bean (Phaseolus vulgaris L.) Varieties in Kafa and Sheka Zones, South Western Ethiopia Asian Journal of Plant Science and Research, 11 (2): 33-36.

[6] Bucheyeki, T. L., \& Mmbaga, T. E. (2013). On-farm evaluation of beans varieties for adaptation and adoption in Kigoma region in Tanzania. International Scholarly Research Notices, 2013.

[7] Centro International de Agricultura Tropical (CIAT) (1986a).
The cultivated species of phaseoulus: study guide to be used as supplement to the audotutorial unit on the same topic. Cali, Colombia. CLAT.

[8] Cooper, M., Byth, D. E., \& Hammer, G. L. (1996). Understanding plant adaptation to achieve systematic applied crop improvement a fundamental challenge. Plant adaptation and crop improvement, 5-23.

[9] Crossa, J. (1990). Statistical analyses of multilocation trials. In Advances in agronomy (Vol. 44, pp. 55-85). Academic Press.

[10] Crow, G. H. (2010). Multi-environment experiments in agriculture. University of Manitoba, Department of Animal Science CSSA Statistics workshop.

[11] Deresa Shumi, Demissie Alemayehu and Tekalign Afeta 2020. Adaptation Study of Improved Chickpea (Cicer arietinum L.) Varieties at Mid and highland of Guji zone, Southern Ethiopia Journal of Agricultural Science and Research, Vol. 6 (1), pp. 42-46.

[12] Gomez, K. A., \& Gomez, A. A. (1984). Statistical procedures for agricultural research. John Wiley \& Sons.

[13] Imru Assefa, 1985. Bean production in Ethiopia. In: Regional workshop on potential for field beans (Phaseolus vulgaris L.) in West Asia and North Africa. Aleppo, Syria. 1983.

[14] Keba, H. A. (2018). Adaptability evaluation of common bean (Phaseolus vulgaris L.) genotypes at western Ethiopia. Journal of Agricultural Biotechnology and Sustainable Development, 10 (7), 140-146.

[15] Shimelis Alemayehu and Alemu Doda (2018). Adaptation Study of Improved Common Bean (Phaseolus vulgaris L.). Varieties under irrigated Condition in the middle Awash Rift Valley Werer Ethiopia. Academic Research Journal of Agricultural Science and Resea Vol. 7 (1), pp. 1-7.

[16] Tigerstedt, P. M. A. (1994). Adaptation, variation and selection in marginal areas Euphytica, 77 (3), 171-174.

[17] Wricke, G., \& Weber E. (1986). Quantitative genetics and selection in plant breeding. Gruyter. 